\title{
Survival of Lactobacillus sakei during heating, drying and storage in the dried state when growth has occurred in the presence of sucrose or monosodium glutamate
}

\author{
Vânia Ferreira, Vânia Soares, Cristina Santos, Joana Silva, Paul A. Gibbs \& Paula \\ Teixeira* \\ Escola Superior de Biotecnologia, Universidade Católica Portuguesa, Rua Dr. António Bernardino de \\ Almeida, 4200-072 Porto, Portugal \\ *Author for correspondence (Fax: + 351 225090351; E-mail: paula@esb.ucp.pt)
}

Key words: drying, Lactobacillus sakei, solutes accumulation, viability

\begin{abstract}
Spray-dried cells of Lactobacillus sakei CTC 494 survived ca. 60\% longer in the spray dried state when cells were grown in the presence of $20 \mathrm{~g}$ sucrose $1^{-1}$ or $12.5 \mathrm{~g}$ monosodium glutamate $\mathrm{l}^{-1}$. No significant differences were observed in viability during storage in the freeze dried state with the addition of these compounds to the growth medium, nor in survival during a heat treatment $\left(55^{\circ} \mathrm{C}\right)$. Both sucrose and glutamate in the growth medium suppressed intracellular accumulation of total amino acids and changed the overall pattern of the individual amino acids. Glutamate in the growth medium enhanced intracellular glutamate by ca. $38 \%$.
\end{abstract}

\section{Introduction}

Lactobacillus sakei occurs naturally on meat, meat products and fish products. L. sakei CTC 494 is a potential probiotic strain because of its high degree of adhesion to chicken intestinal epithelial cells, antagonistic activity against some foodborne pathogens, including L. monocytogenes, and its capacity to decrease biogenic amine accumulation during sausage fermentation (Hugas et al. 1995).

Bulk production of $L$. sakei, ready to use as an inoculum in food fermentations, would therefore be very useful. For industrial use, lactic acid bacteria (LAB) are often preserved in a frozen or dried state; the latter preparations having lower transport and storage costs (Gardiner et al. 2000). Considering the cost of producing large quantities of dried starters and the costs involved in their transport and storage, spray drying is more effective than other drying methods. A disadvantage of drying is the loss of viability/activity during subsequent storage, especially when cultures are kept at room temperature (Carvalho et al. 2004). Various agents are therefore usually added to the growth or drying media in order to minimize these effects. The choice of an appropriate growth medium is therefore of fundamental importance to increase the survival of organisms during and after drying (Welsh 2000, Silva et al. 2004) as compatible solutes are probably accumulated intracellularly (Linders et al. 1997).

Sucrose and monosodium glutamate (MSG) have a positive effect during storage of various dried LAB (Carvalho et al. 2002, Silva et al. 2004). The degree of protection during storage afforded by a given additive, however, was demonstrated to be species- and strain-dependent. The aim of the 
present study was to investigate the effect of sucrose and MSG added to the growth medium on the survival of L. sakei CTC 494 during heating, drying and subsequent storage in the dried state. To seek any underlying mechanisms of cell protection during heating, drying or storage in the dried state, the intracellular amino acid contents of cells grown in the presence of sucrose and glutamate were compared with that of control cells grown in MRS.

\section{Materials and methods}

\section{Organism and media}

Lactobacillus sakei CTC 494 was supplied by Dr Marta Hugas (Spain). It was grown in De Man, Rogosa, Sharpe (MRS) broth at $37^{\circ} \mathrm{C}$ for $24 \mathrm{~h}$ and then inoculated $(1 \% \mathrm{v} / \mathrm{v})$ into MRS broth, and MRS broth with either $20 \mathrm{~g}$ sucrose $1^{-1}$ or $12.5 \mathrm{~g}$ monosodium glutamate (MSG) $1^{-1}$. These cultures were incubated at $37{ }^{\circ} \mathrm{C}$ for $24 \mathrm{~h}$ and cells harvested by centrifugation at $7000 \times g$ for $15 \mathrm{~min}$ $\left(4^{\circ} \mathrm{C}\right)$.

\section{Preparation of extracts for HPLC analysis}

Harvested cells were washed 3 times by centrifugation with phosphate buffer $(0.1 \mathrm{M}, \mathrm{pH} 7)$. Wet cell pellets (ca. 4-8 g) were extracted as described by Silva et al. (2004). Extracts were analysed by HPLC, using a C18 column and a scanning fluorescence detector. Identification and quantification of amino acids was performed according to Souffleros et al. (1998).

\section{Stress treatments}

Wet cell pellets were re-suspended to the original volume in $11 \%(\mathrm{w} / \mathrm{v})$ reconstituted skim-milk powder.

\section{Heating}

One $\mathrm{ml}$ of cell suspensions was transferred to $49 \mathrm{ml}$ of sterilized Ringer's solution at $55^{\circ} \mathrm{C}$ and maintained at this temperature for $20 \mathrm{~min}$. At regular intervals, samples were taken and immediately diluted in sterile Ringer's solution at room temperature.
Spray drying

Cell suspensions were spray dried as previously reported by Silva et al. (2004). The powder was stored in air at $20^{\circ} \mathrm{C}$.

Freeze drying

Cell suspensions $(15 \mathrm{ml})$ were desiccated under vacuum (50 mTorr for $48 \mathrm{~h}$ ) in a freeze-drier according to Carvalho et al. (2004). Dried cells were stored at room temperature in air at $20{ }^{\circ} \mathrm{C}$.

\section{Enumeration of survivors}

Survivors before and at appropriate intervals during heating and storage (dried samples were resuspended to the original volume with sterile Ringer solution and allowed to rehydrate for 2 min with vigorous shaking), were enumerated by the drop count technique on MRS agar incubated aerobically at $37^{\circ} \mathrm{C}$ for $24 \mathrm{~h}$.

\section{Statistical analyses}

Each experiment was repeated twice. Viable counts on MRS agar were converted to log c.f.u. $\mathrm{ml}^{-1}$. Statistical analyses of survival during heating and during storage in the dried state were performed by the ANOVA methodology using as independent variable the heating or storage time. Differences were considered significant at $p<0.05$. The error bars in Figures 1 and 2 indicate the mean standard deviations for the data points.

\section{Results and discussion}

Survival of dried L. sakei during storage was greater following freeze-drying rather than spraydrying (Figure 1). Similar results were demonstrated by Wang et al. (2004). This was attributed to the higher water content or higher water activity $\left(a_{\mathrm{W}}\right)$ of the dried product; organisms are more sensitive to environmental stresses at high $a_{\mathrm{W}}$ (Karel 1975).

The effects of sucrose or MSG in the growth medium of $L$. sakei vary according to the stress being imposed. There were no significant differences $(p<0.05)$ between the thermotolerances (Figure 2) and survival of both drying processes 

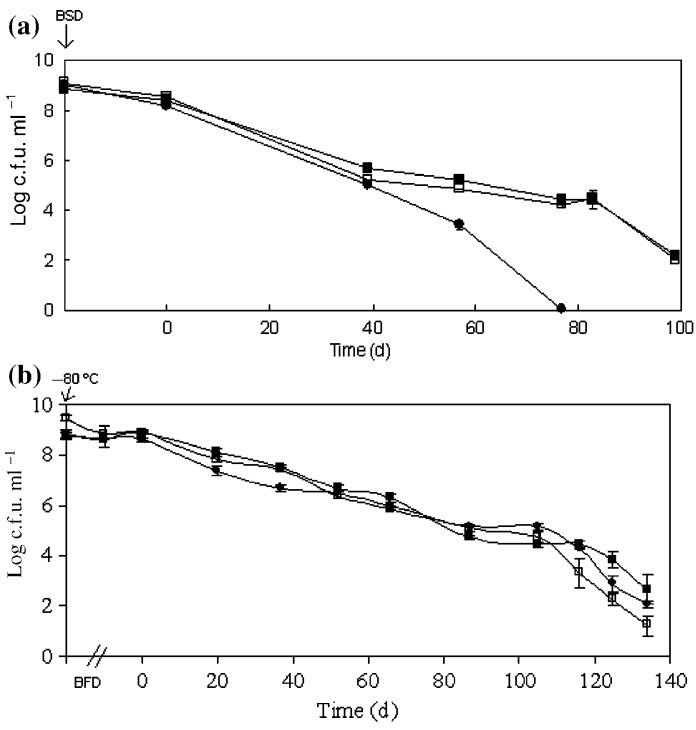

Fig. 1. Effect of the presence of sucrose and MSG in the growth medium on the survival of Lactobacillus sakei CTC 494 during storage in (a) the spray-dried state and in (b) the freezedried state. The error bars indicate the mean standard deviations for the data points (BSD, before spray drying; BFD, before freeze drying). MRS supplemented with $20 \mathrm{~g}$ sucrose $\mathrm{1}^{-1}$, 口; MRS, ๑, MRS supplemented with $12.5 \mathrm{~g} \mathrm{MSG}^{-1}, \square$.

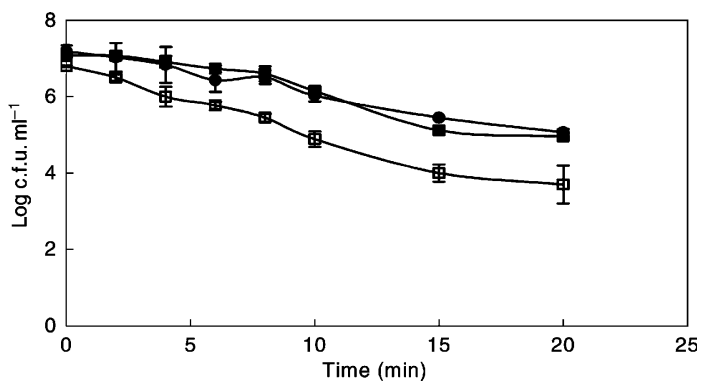

Fig. 2. Effect of the presence of sucrose and monosodium glutamate in the growth medium on the survival of Lactobacillus sakei CTC 494 during heating in sterile Ringer's solution at $55^{\circ} \mathrm{C}$. The error bars indicate the mean standard deviations for the data points. MRS supplemented with $20 \mathrm{~g}$ sucrose $\mathrm{l}^{-1}$, 口; MRS, - MRS supplemented with $12.5 \mathrm{~g}$ monosodium glutamate $1^{-1} \square$.

(Figure 1) by cells grown in the three different media. Extended cellular survival during storage of the spray-dried but not of the freeze-dried cells (ca. double for MRS-grown cells; ca. 40\% for supplemented MRS-grown cells; Figure 1) was observed following growth in the presence of these compounds. Any protective effect conferred by these compounds during the drying processes may have been masked by the protective effect of milk components (Teixeira et al. 1994, Carvalho et al. 2003).

During drying processes, cells are subjected to low $a_{\mathrm{W}}$ conditions. Accumulation of compatible solutes would therefore be expected to enhance survival during those processes. As microorganisms are unlikely to be able to accumulate compatible solutes during the short drying period, these solutes should be accumulated before drying, i.e. during the growth phase. In addition to osmotic stress, during spray-drying cells are exposed to stressful temperatures. Accumulation of compatible solutes has been shown to be associated with increased thermotolerance of various organisms (Welsh 2000).

A higher concentration of glutamate in L. sakei was found when MSG was present in the growth medium (Table 1), contributing substantially to the overall amino acid/solute pool. However, accumulation of many of the other amino acids was heavily suppressed (data not shown), e.g. no glutamine was detected, alanine was suppressed to ca. $9 \%$, valine to ca. $14 \%$ and aspartic acid to ca. $25 \%$ of the values found in control cells (grown in MRS). Glutamate has already been shown to be accumulated by osmotically stressed $L$. plantarum (Kets \& Bont 1997), in agreement with the general observations that glutamate levels are markedly increased as part of the osmo-adaptive response. Glutamate is probably a counterion for $\mathrm{K}^{+}$ to balance the intracellular charge accumulated by bacteria under osmotic stress (Kets et al. 1997).

Cells grown in MRS supplemented with sucrose, showed a similar pattern of intracellular amino acids to those in control cells, except that serine and methionine levels were enhanced by ca. $50 \%$, glutamine levels by ca. $80 \%$, no arginine was detected, and lower levels of glutamate and aspartate were found (ca. 40-50\% lower than in control cells; data not shown). Sucrose as an osmolyte accumulated by stressed bacteria is advantageous in that as a non-reducing sugar, it does not undergo Maillard reactions with the amino groups of proteins (Page-Sharp et al. 1999). Sucrose accumulated by Lactobacillus bulgaricus resulted in significantly enhanced survival during heating and during storage of dried cells (Silva et al. 2004).

The mechanisms responsible for cellular inactivation and protection during drying and storage 
Table 1. Effect of growth media on the intracellular amino acid pools in Lactobacillus sakei CTC 494.

\begin{tabular}{llcc}
\hline & \multicolumn{2}{l}{ Growth media } & \\
\cline { 2 - 4 } & MRS & MRSS $^{\mathrm{a}}$ & MRSM $^{\mathrm{b}}$ \\
\hline Total amino acid concentration $\left(\mathrm{mg} \mathrm{g}^{-1}\right.$ wet cells) & $300 \pm 13.2$ & $252 \pm 2.6$ & $138 \pm 6.1$ \\
Glutamate concentration $\left(\mathrm{mg} \mathrm{g}^{-1}\right.$ wet cells) & $40 \pm 1.2$ & $27 \pm 0.6$ & $55 \pm 1$ \\
\hline
\end{tabular}

${ }^{a}$ MRS supplemented with $20 \mathrm{~g}$ sucrose $1^{-1}$.

${ }^{\mathrm{b}}$ MRS supplemented with $12.5 \mathrm{~g}$ monosodium glutamate $1^{-1}$.

are complex and still not understood. However, selection of an appropriate growth medium on a case-by-case basis is essential to maximize survival of the organisms during drying/storage.

\section{Acknowledgements}

This work received partial financial support via project PRAXIS/P/BIO/12147/1998 (FCT, Portugal), co-ordinated by P.T. and P.G. Financial support for J.S. was provided by a PhD fellowship issued by PRAXIS XXI/BD/197131/99.

\section{References}

Carvalho AS, Silva J, Ho P, Teixeira P, Gibbs P, Malcata FX (2002) Survival of freeze-dried Lactobacillus plantarum and L. rhamnosus during storage in the presence of protectants. Biotechnol. Lett. 24: 1587-1591.

Carvalho AS, Silva J, Ho P, Teixeira P, Gibbs P, Malcata FX (2003) Protective effect of sorbitol and monosodium glutamate during storage of freeze-dried lactic acid bacteria. Lait 83: $203-210$

Carvalho AS, Silva J, Ho P, Teixeira P, Gibbs P, Malcata FX (2004) Effects of various sugars added to the growth media upon thermotolerance and survival throughout storage of freeze-dried Lactobacillus delbrueckii ssp. bulgaricus. Biotechnol. Lett. 20: 248-254.

Gardiner GE, O'Sullivan E, Kelly J, Auty MAE, Fitzgerald GF, Collins JK, Ross RP, Stanton C (2000) Comparative survival rates of human-derived probiotic Lactobacillus paracasei and L. salivarius strains during heat treatment and spray drying. Appl. Environ. Microbiol. 66: 2605-2612.

Hugas M, Garriga M, Aymerich MT, Monfort JM (1995) Inhibition of Listeria in dry fermented sausages by the bacteriocinogenic Lactobacillus sakei 494. J. Appl. Bacteriol. 79: $322-330$.

Karel M (1975) Equilibrium and rate considerations in process for food concentration and dehydration. In: Fennema OR, ed. Principles of Food Science: Part II. Physical Principles of Food Preservation. New York: Marcel Dekker, pp. 219-263.

Kets EPW, De Bont JAM (1997) Effect of carnitine on Lactobacillus plantarum subjected to osmotic stress. FEMS Microbiol. Lett. 146: 205-209.

Kets EPW, Groot MN, Galinski EA, De Bont, JAM (1997) Choline and acetylcholine: novel cationic osmolytes in Lactobacillus plantarum. Appl. Microbiol. Biotechnol. 48: 94-98.

Linders LJM, Meedink G, Vańt Riet K (1997) Effect of growth parameters on the residual activity of $L$. plantarum after drying. J. Appl. Microbiol. 82: 683-688.

Page-Sharp M, Behm CA, Smith GD (1999) Involvement of the compatible solutes trehalose and sucrose in the response to salt stress of a cyanobacterial Scytonema species isolated from desert soils. Biochim. Biophys. Acta 1472: 519-528.

Silva J, Carvalho AS, Pereira H, Teixeira P and Gibbs P (2004) Induction of stress tolerance in Lactobacillus delbrueckii ssp. bulgaricus by the addition of sucrose to the growth medium. J. Dairy Res. 71: 121-125.

Soufleros E, Barrios, ML, Bertrand A (1998) Correlation between the content of biogenic amines and other wine compounds. Am. J. Enol. Vitic. 49: 266-277.

Teixeira P, Castro H, Kirby R (1994) Inducible thermotolerance in Lactobacillus bulgaricus. Lett. Appl. Microbiol. 83: 218-221.

Wang Y, Yu R, Chou C (2004) Viability of lactic acid bacteria and bifidobacteria in fermented soymilk after drying, subsequent rehydration and storage. Int. J. Food Microbiol. 93: 209-217.

Welsh DT (2000) Ecological significance of compatible solute accumulation by micro-organisms: from single cells to global climate. FEMS Microbiol. Rev. 24: 263-290. 